\title{
An efficient way for the synthesis of covalent Strandberg-type phosphomolybdate compound $\mathrm{H}_{6} \mathrm{P}_{2} \mathrm{Mo}_{5} \mathrm{O}_{23}$
}

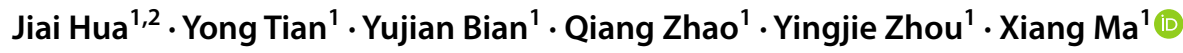

Received: 27 November 2019 / Accepted: 28 January 2020 / Published online: 31 January 2020

(c) Springer Nature Switzerland AG 2020

\section{Abstract}

A covalent Strandberg-type phosphomolybdate $\mathrm{H}_{6} \mathrm{P}_{2} \mathrm{Mo}_{5} \mathrm{O}_{23}$ (EPM) was synthesized by applied ethanediamine (en) as a template agent. Besides, the $\mathrm{pH}$ value and $\mathrm{Mn}^{2+}$ were also the important factors in composing EPM. The structure of EPM was characterized by elemental analyses, X-ray powder diffraction, $\mathrm{X}$-ray photoelectron spectra, IR spectrum, and single-crystal X-ray diffraction. Structural analysis shows that EPM consists a $\mathrm{H}_{6} \mathrm{P}_{2} \mathrm{Mo}_{5} \mathrm{O}_{23}$ cluster and two en molecules as lattice fillers. As a case of molybdenum oxide, EPM exhibits thermal instability even under low temperature conditions, which is more similar to covalent compound than ionic compound.

Graphic abstract A thermo-unstable covalent Strandberg-type precursor was successfully synthesized, and the synthesis method was innovative, involving $\mathrm{pH}$ value, catalyst and template synthesis, which provided good synthesis experience for future experiments.

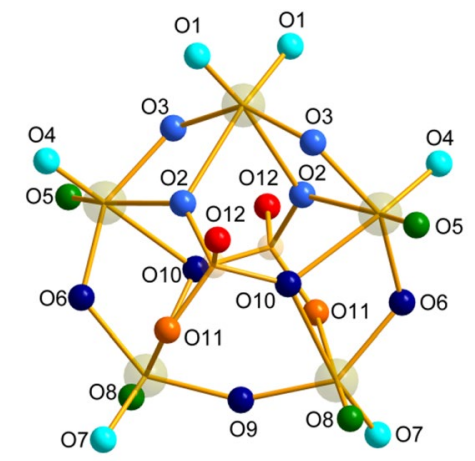

Protonation level $(\Sigma \mathrm{H})$ of $\mathrm{O}$ atoms in EPM

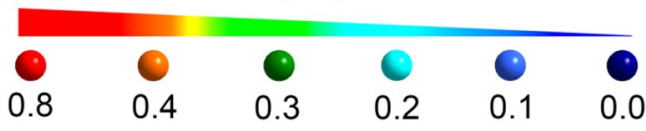

Keywords Phosphomolybdate · Strandberg-type cluster · Thermochromism · Crystal structure analysis · Template synthesis

Electronic supplementary material The online version of this article (https://doi.org/10.1007/s42452-020-2124-6) contains supplementary material, which is available to authorized users.

$\bowtie$ Jiai Hua, JiaiHua01660@163.com; $\bowtie$ Xiang Ma, maxiang6012@163.com | ${ }^{1}$ Chemistry and Chemical Engineering Department, Taiyuan Institute of Technology, Taiyuan 030008, People's Republic of China. ${ }^{2}$ State Key Laboratory of Coordination Chemistry, Nanjing University, Nanjing 210023, People's Republic of China. 


\section{Introduction}

Polyoxometalates (POMs) are a typical class of metal-oxygen clusters. POMs possesses multitudinous structures and fascinating properties applied in various fields such as fluorescence, magnetism, catalysis, medicine materials and nano-science [1-3].

In varieties of building blocks, Strandberg-type $\left(\left[\mathrm{P}_{2} \mathrm{Mo}_{5} \mathrm{O}_{23}\right]^{6-}\right)$ fragment have several inherent advantages such as nano-size, nucleophilic oxygen-enriched surface and poly-bond-making sites, endowing it with the ability to serve as bulky polydentate ligands to incorporate in multiple metal ions with flexible coordination modes [4-12]. Moreover, researches have indicated recently that the POMs with Strandberg-type fragment have an excellent oxidation catalytic capacity, for example, oxidation of styrene and ketalization of cyclohexanone with glycol $[13,14]$. Hence, these properties of $\left[\mathrm{P}_{2} \mathrm{Mo}_{5} \mathrm{O}_{23}\right]^{6-}$ cluster may be beneficial to catalyze the production of reactive oxygen species (ROS) and have broad prospects being utilized in catalysis, medicine materials, etc.

However, In contrast to the Keggin-, Dowson- and Anderson-type structures of polyoxomolybdates (POMos), the researches on Strandberg-type POMos are lagging behind [15]. Furthermore, hitherto, the synthetic methods of Strandberg-type POMos are most rely on hydrothermal synthesis method [4, 5, 7-14], which provides us a good opportunity to exploit a simpler, less energy-intensive synthesis method in composing Strandberg-type structure containing compounds, especially the synthesis method of $\left[\mathrm{P}_{2} \mathrm{Mo}_{5} \mathrm{O}_{23}\right]^{6-}$ precursor.

Herein, we report a convenient synthesis of Strandberg-type building block, $\mathrm{H}_{6} \mathrm{P}_{2} \mathrm{Mo}_{5} \mathrm{O}_{23}$ (abbreviated as EPM). The optimum synthesis method were verified by parallel experiments. The EPM consists a $\left[\mathrm{H}_{6} \mathrm{P}_{2} \mathrm{Mo}_{5} \mathrm{O}_{23}\right]$ cluster and two ethanediamine (en) molecules. Notably, EPM is thermal unstable being heated and extremely difficult to dissolve in water, which may indicate that EPM is a covalent compound rather than an ionic compound.

\section{Experimental}

\subsection{Materials}

Reagents used in this study were all of analytical grade, purchased from commercial suppliers and used as received unless otherwise stated. Methanamine, trimethylamine, triethylamine, aniline, propane-1,3-diamine, propane-1,2-diamine, and 1,4,7,10-tetraazacyclododecane were purchased from Macklin Reagent Inc. (P. R. China). $\mathrm{MnCl}_{2} \cdot 2 \mathrm{H}_{2} \mathrm{O}, \mathrm{NaMoO}_{4} \cdot 2 \mathrm{H}_{2} \mathrm{O}, \mathrm{Na}_{2} \mathrm{HPO}_{4} \cdot 12 \mathrm{H}_{2} \mathrm{O}$, $\mathrm{NH}_{4} \mathrm{Cl}$ and en were purchased from $\mathrm{J} \& \mathrm{~K}$ Scientific Inc. (P. R. China). All the solutions were prepared with ultrapure water filtered through Milli-Q academic system according to previous reports [16].

\subsection{Physical measurements}

X-ray powder diffraction (XRPD) measurements were obtained using a Philips X'pert-MPD instrument with Cu-Ka radiation $(\lambda=1.54056 \AA)$ at $293 \mathrm{~K}$. IR spectra were obtained from a sample powder palletized with $\mathrm{KBr}$ or dissolved in chloroform on a Nicolet 170 SXFT-IR spectrophotometer over the range $4000-400 \mathrm{~cm}^{-1}$. Elemental analyses for $\mathrm{C}, \mathrm{H}$ and $\mathrm{N}$ were performed on a Perkin-Elmer $240 \mathrm{C}$ elemental analyzer. The single crystal data of EPM were collected on a Bruker CCD, Apex-II diffractometer with graphite monochromated Mo-Ka $(\lambda=0.71073 \AA)$ radiation at room temperature. Routine Lorentz and polarization corrections were applied and an absorption correction was performed using the SADABS program [17]. The structure was solved by direct methods and refined using full-matrix least squares on $F^{2}$. All calculations were performed using the SHELXL-97 program package [18]. Elemental analysis was performed on a PQEXCell ICP-MS.

\subsection{Synthesis}

Two solutions were prepared separately. Solution A: $\mathrm{Na}_{2} \mathrm{MoO}_{4} \cdot 2 \mathrm{H}_{2} \mathrm{O}(2.420 \mathrm{~g}, 10.00 \mathrm{mmol})$ and $\mathrm{Na}_{2} \mathrm{HPO}_{4} \cdot 12 \mathrm{H}_{2} \mathrm{O}$ $(2.400 \mathrm{~g}, 6.70 \mathrm{mmol})$ were dissolved in water $(30 \mathrm{~mL})$ under stirring. Solution $\mathrm{B}: \mathrm{MnCl}_{2} \cdot 2 \mathrm{H}_{2} \mathrm{O}(1.620 \mathrm{~g}, 10.00 \mathrm{mmol})$ and en $(0.10 \mathrm{~mL}, 1.50 \mathrm{mmol})$ were added to water $(30 \mathrm{~mL})$ under stirring. The resulting mixture of $B$ is added to solution $A$. The mixture was stirred for $10 \mathrm{~min}$ at room temperature and then the $\mathrm{pH}$ value was adjusted to 5.2 by adding $6 \mathrm{~mol} \mathrm{~L}^{-1} \mathrm{HCl}$ dropwise. The solution was kept at $85^{\circ} \mathrm{C}$ for $1 \mathrm{~h}$ and filtered when it was still hot. The filtrate was allowed to evaporate in an open beaker at room temperature. About 1 day, Colorless crystal EPM formed. (Yield: ca $39 \%$ based on $\mathrm{Na}_{2} \mathrm{MoO}_{4} \cdot 2 \mathrm{H}_{2} \mathrm{O}$ ). Elemental analysis (\%) calcd for $\left\{\left[\mathrm{C}_{2} \mathrm{~N}_{2} \mathrm{H}_{8}\right]_{2}\right\}\left[\mathrm{H}_{6} \mathrm{P}_{2} \mathrm{Mo}_{5} \mathrm{O}_{23}\right]: C 4.64, \mathrm{~N}$ 5.41, P 5.98, Mo 46.30; found: C 4.55, N 5.28, P 5.88, Mo 46.05.

\subsection{X-ray data collection and structure refinement}

Intensity data of EPM was collected on a Bruker Apex-2 diffractometer with a CCD detector using graphite 
monochromatized Mo-Ka radiation $(\lambda=0.71073 \AA)$ at 296 K. Date integration was performed using SAINT [19]. Routine Lorentz and polarization corrections were applied. Multiscan absorption corrections were performed using SADABS [17]. The structure was solved by direct methods and refined using full-matrix least squares on $F^{2}$. The remaining atoms were found from successive full-matrix least-squares refinements on $F^{2}$ and Fourier syntheses. All calculations were performed using the SHELXL-97 program package [18]. No hydrogen atoms associated with the water molecules were located from the difference Fourier map. Positions of the hydrogen atoms attached to the carbon and nitrogen atoms were geometrically placed. All hydrogen atoms were refined isotropically as a riding mode using the default SHELXTL parameters. A summary of crystal data and structure refinements for EPM is listed in Table S1.

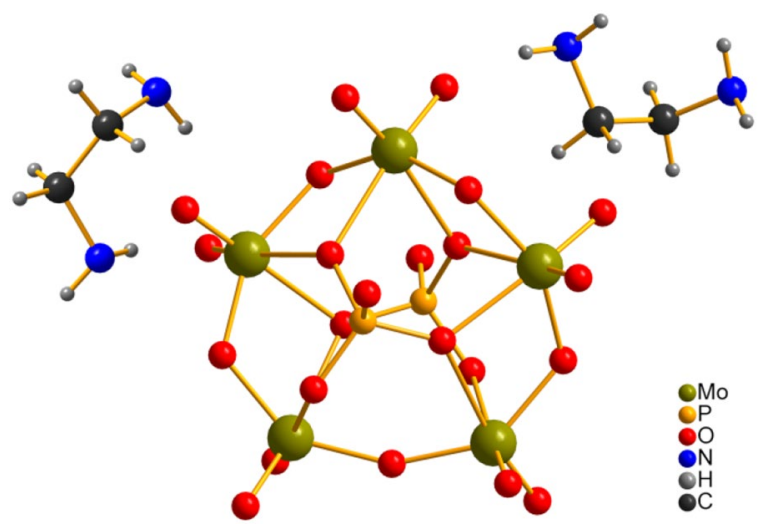

Fig. 1 Ball-and-stick representation of $\left\{\left[\mathrm{C}_{2} \mathrm{~N}_{2} \mathrm{H}_{8}\right]_{2}\right\}\left[\mathrm{H}_{6} \mathrm{P}_{2} \mathrm{Mo}_{5} \mathrm{O}_{23}\right]$

Fig. 2 a, b Ball-and-stick representation of Strandbergtype fragment via $\mathrm{X}$ or $\mathrm{Z}$ axis. c, d Polyhedral representation of Strandberg-type fragment $\left\{\left[\mathrm{P}_{2} \mathrm{Mo}_{5} \mathrm{O}_{23}\right]^{6-}\right\}$ via $\mathrm{X}$ or $\mathrm{Z}$ axis. e The anatomical view of the Strandberg-type fragment

\section{Results and discussion}

\subsection{Crystal structure and Synthetic discussion}

The structure of EPM was characterized by single-crystal X-ray diffraction analysis. The crystallographic data, selected bond lengths and angles are summarized in Tables S2 and S3. Detailed information has been deposited at the Cambridge Crystallographic Data Centre with a CCDC number of 1920376. X-ray structural analysis (see Fig. 1) shows that the molecular structural unit of EPM consists one $\left\{\mathrm{P}_{2} \mathrm{Mo}_{5} \mathrm{O}_{23}\right\}$ cluster and two en molecules. As shown in Fig. 2 , the geometry of $\left\{\mathrm{P}_{2} \mathrm{Mo}_{5} \mathrm{O}_{23}\right\}$ cluster can be deemed as a puckered ring of five nearly coplanar cornersharing/edge-sharing distorted $\mathrm{MoO}_{6}$ octahedra [Mo-O:

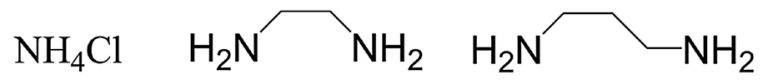

ammonium chloride ethanediamine propane-1,3-diamine

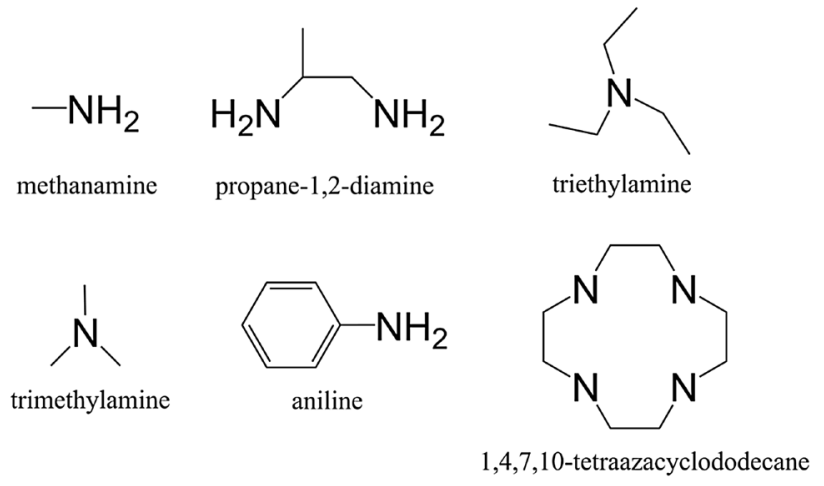

Fig. 3 Diagrams of the structures of various amines used in parallel experiments

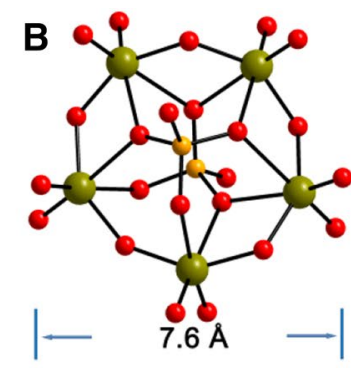

D
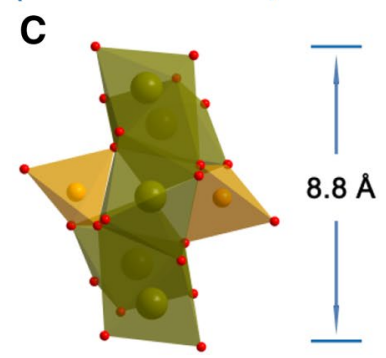

$\mathbf{E}$

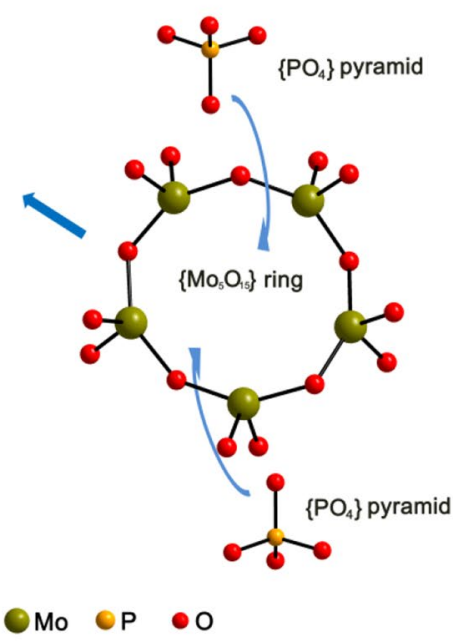

SN Applied Sciences 
1.687(2)-2.393(2) $\AA$ ] with two capping $\mathrm{PO}_{4}$ tetrahedra [P-O: 1.505(5)-1.561(5) $\AA$ ] on both poles of the $\left\{\mathrm{Mo}_{5} \mathrm{O}_{21}\right\}$ ring centers, which size fits the nanometer scale.

In the synthesis process, there are three key factors:

Firstly, the usage of en to be template agent is one key factor in composing EPM. A series of different types of amines (see Fig. 3) were used and tested in the same way, however, no other amines except en could achieve the target product. These results may indicated that en is the template agent inducing the formation of Strandberg-type fragment $\left[\mathrm{P}_{2} \mathrm{Mo}_{5} \mathrm{O}_{23}\right]^{6-}$.

Secondly, $\mathrm{Mn}^{2+}$ is the most suitable catalyst. Without the presence of $\mathrm{Mn}^{2+}$, the reaction yield is very low, which almost no Strandberg-type fragment $\left[\mathrm{P}_{2} \mathrm{Mo}_{5} \mathrm{O}_{23}\right]^{6-}$ formed. When other metal ions are used instead of $\mathrm{Mn}^{2+}$, the experimental phenomena are different. If $\mathrm{s}$-block metal ions are used, for example $\mathrm{Mg}^{2+}, \mathrm{MoO}_{4}{ }^{2-}$ in the reaction will be reduced, and the solution will turn inky blue, with no target product finally formed. If metal ions in the dsblock are used to replace $\mathrm{Mn}^{2+}$, such as $\mathrm{Cu}^{2+}$ etc., although $\left[\mathrm{P}_{2} \mathrm{Mo}_{5} \mathrm{O}_{23}\right]^{6-}$ can still be generated, the side effect is that they will be directly connected with the ions to generate transition-metal substituted Strandberg-type POMos [6, 15] instead of formation of isolated Strandberg-type structure. If metal ions in d-block, such as $\mathrm{Cr}^{3+}$, replace $\mathrm{Mn}^{2+}$, some impurity fuchsia crystal $\left(\mathrm{CrPO}_{4}\right)$ formed instead of the formation of $\left[\mathrm{P}_{2} \mathrm{Mo}_{5} \mathrm{O}_{23}\right]^{6-}$ clusters. The results may indicate that $\mathrm{Mn}^{2+}$ is the most suitable ions in this reaction system.

Finally, $\mathrm{pH}$ is another important factor. As shown in Fig. 4, the results showed that EPM was generated from 3.5 to 7.0 , and the crystal morphology was best when the initial $\mathrm{pH}$ was 5.2. The EPM yield was the highest when the

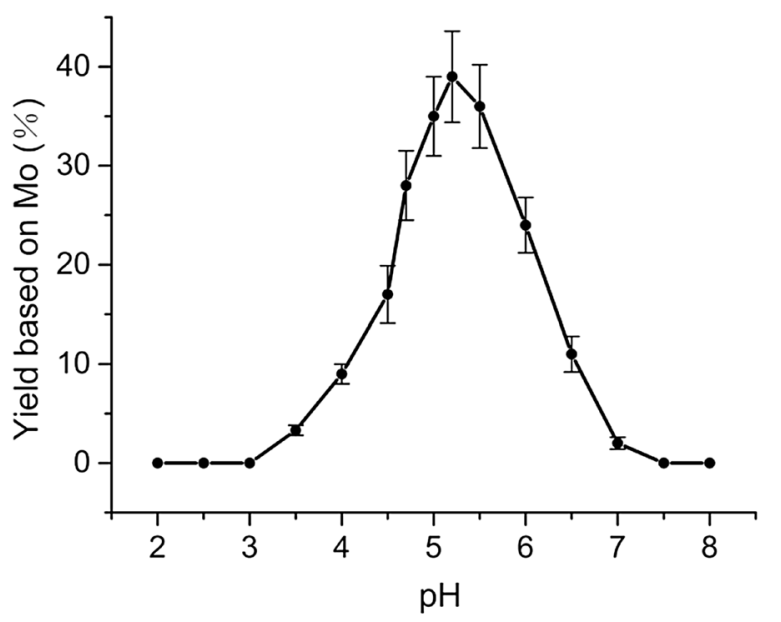

Fig. 4 The relationship between the yield of EPM and $\mathrm{pH}$ value of the system (based on $\mathrm{Na}_{2} \mathrm{MoO}_{4} \cdot 2 \mathrm{H}_{2} \mathrm{O}$ ) initial $\mathrm{pH}$ was 4.8-5.5. When the $\mathrm{pH}$ value is higher than 7.0 or lower than 3.5, no EPM crystals were obtained.

Although the synthesis method and structure of Strandberg-type POM have been reported for decades, EPM does have two characteristics compared with previous reports:

1. EPM was synthesized by conventional aqueous solution method instead of hydrothermal method [20, 21], which greatly reduces the requirement of EPM synthesis equipment and energy consumption.

2. According to the calculation of XPS and BVS, we can conclude that the ethylenediamine molecule in EPM is not protonated, that is, EPM is not an ionic compound but a covalent compound, which is the essential difference between EPM and previous reports [20, 21]. The thermal instability and poor water solubility $(\leq 1 \mathrm{mg}$ $\mathrm{L}^{-1}$ ) of EPM can be verified from some aspects.

Besides, an easily available building block will greatly enhance the research prospects in this area [22]. Hence, this work may have important application prospects in the synthesis of novel Strandberg-type compounds.

\subsection{X-ray powder diffraction (XRPD) and X-ray photoelectron spectra (XPS)}

The phase purity of EPM was confirmed by a comparison of the experimental X-ray powder diffraction (XRPD) pattern with the simulated pattern from single-crystal $X$-ray diffraction (Fig. 5). Owing to the variation in the preferred orientation of the powder sample in the experimental XRPD, the intensities of the experimental and simulated XRPD patterns are different.

The investigation using X-ray photoelectron spectra (XPS) has been carried out to detect the valences of Mo and P. As shown in Fig. 6a, there are two broad peaks

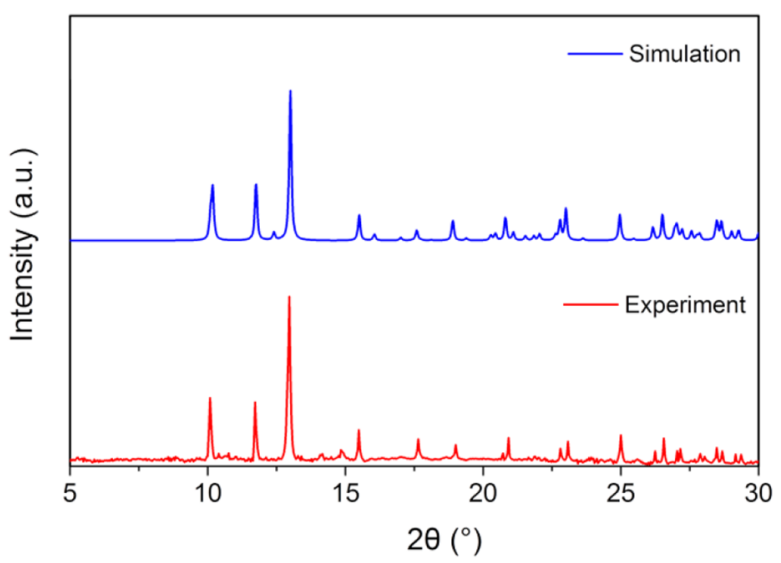

Fig. 5 Comparison of the simulated and experimental XRPD patterns of EPM 

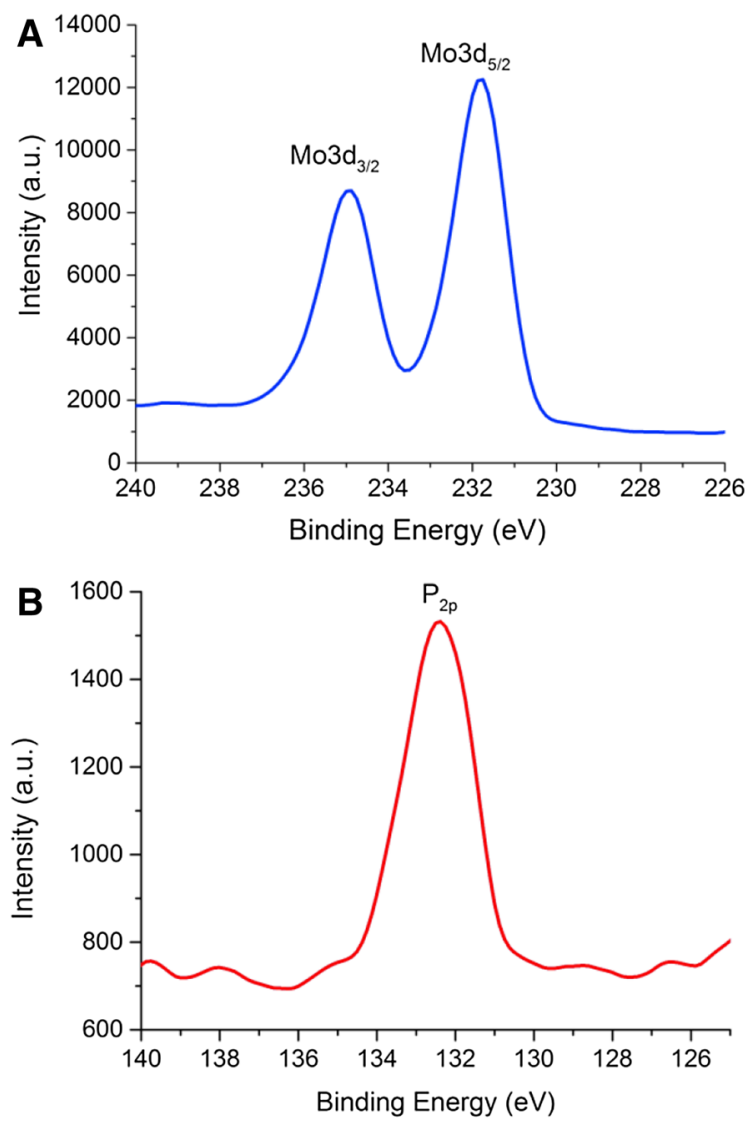

Fig. 6 XPS spectra of Mo and P. a Mo $\mathrm{Mo}^{6+} 3 \mathrm{~d}_{5 / 2}(231.6 \mathrm{eV})$ and $\mathrm{Mo}^{6+}$ $3 d_{3 / 2}(235.0 \mathrm{eV}) ; \mathbf{b} \mathrm{P}^{5+} 2 p(132.2 \mathrm{eV})$

located at 235.0 and $231.6 \mathrm{eV}$, which were assigned to Mo $3 d_{3 / 2}$ and Mo $3 d_{5 / 2}$, respectively [23]. As shown in Fig. 6b, there is one peak located at $132.2 \mathrm{eV}$, which was assigned to $P 2 P[24]$. The results show that the valence $M o$ and $P$ are +6 and +5 in EPM, respectively [15].

\subsection{Bond valence sums ( $\Sigma \mathrm{s}$ ) calculation (BVS)}

The bond valence sums $(\boldsymbol{\Sigma} \mathrm{s})$ and the protonation level $(\boldsymbol{\Sigma} \mathrm{H})$ of oxygen atoms in EPM were further calculated according to the reported methods $[25,26]$. Briefly, the oxidation states of the oxygen atoms in EPM were calculated on the following formula, which could be used to estimate the protonation of oxygen atoms:

$V_{i}=\sum_{j} s_{i j}=\sum_{j} \exp \left(\frac{r_{0}^{\prime}-r_{i j}}{B}\right)$

where $r_{0}^{\prime}$ represents the theoretical value of bond distance between two atoms, and $r_{i j}$ represents the observed values of bond distance that are listed in Table S2; B was set to 0.37 [27]. The theoretical value of $\mathrm{Mo}-\mathrm{O}$ and $\mathrm{P}-\mathrm{O}$ from literatures, which the $\mathrm{r}_{0}^{\prime}\left(\mathrm{Mo}^{6+}-\mathrm{O}\right)$ is $1.907 \AA, \mathrm{r}_{0}^{\prime}\left(\mathrm{P}^{5+}-\mathrm{O}\right)$ is 1.607 $\AA$ [27]. Based on the observed value of bond distance of EPM, the $\Sigma s$ and $\Sigma \mathrm{H}$ of EPM can be calculated and the results are summarized in Tables 1 and 2 and shown in Fig. 7. Thus, we can conclude that the protonation level of oxygen atoms in the EPM.

Since the POMs fragment has high negative charges and rich basic surface oxygen atoms, they can easily been protonated [25]. The 23 oxygen atoms in EPM can be classified into terminal $\mathrm{O}_{t}$, bridging $\mu_{2}-\mathrm{O}$, and $\mu_{3}-\mathrm{O}$. The $\mathrm{O}$ atoms with $\Sigma \mathrm{H}$ of $0.2-0.8$ could act as $\mathrm{H}$-donors owing to the delocalized protons on them, whereas the $\mathrm{O}$ atoms with

Table $2 \boldsymbol{\Sigma} \mathrm{H}$ of $\mathrm{O}$ atom in EPM

\begin{tabular}{llllll}
\hline Atom & $\boldsymbol{\Sigma} \mathrm{H}$ & Atom & $\boldsymbol{\Sigma} \mathrm{H}$ & Atom & $\boldsymbol{\Sigma} \mathrm{H}$ \\
\hline $\mathrm{O} 1$ & 0.265 & $\mathrm{O} 5$ & 0.369 & $\mathrm{O} 9$ & 0.108 \\
$\mathrm{O} 2$ & 0.057 & $\mathrm{O} 6$ & 0.091 & $\mathrm{O} 10$ & 0.066 \\
$\mathrm{O} 3$ & 0.163 & $\mathrm{O} 7$ & 0.222 & $\mathrm{O} 11$ & 0.408 \\
$\mathrm{O} 4$ & 0.222 & $\mathrm{O} 8$ & 0.320 & $\mathrm{O} 12$ & 0.833 \\
\hline
\end{tabular}

Table 1 Bond valence and $\Sigma \mathrm{s}$ of Mo, $\mathrm{P}$ in EPM

\begin{tabular}{llllllll}
\hline Bond & Valence & Bond & Valence & Bond & Valence & Atom & $\Sigma s$ \\
\hline $\mathrm{Mo}(1)-\mathrm{O}(1)$ & 1.735 & $\mathrm{Mo}(1)-\mathrm{O}(2)$ & 0.335 & $\mathrm{Mo}(1)-\mathrm{O}(3)$ & 0.946 & & \\
$\mathrm{Mo}(1)-\mathrm{O}(1) \#$ & 1.735 & $\mathrm{Mo}(1)-\mathrm{O}(2) \#$ & 0.335 & $\mathrm{Mo}(1)-\mathrm{O}(3) \#$ & 0.946 & & \\
& & & & & & $\mathrm{Mo} 1$ & 6.034 \\
$\mathrm{Mo}(2)-\mathrm{O}(2)$ & 0.329 & $\mathrm{Mo}(2)-\mathrm{O}(3)$ & 0.891 & $\mathrm{Mo}(2)-\mathrm{O}(4)$ & 1.778 & & \\
$\mathrm{Mo}(2)-\mathrm{O}(5)$ & 1.631 & $\mathrm{Mo}(2)-\mathrm{O}(6)$ & 0.987 & $\mathrm{Mo}(2)-\mathrm{O}(10)$ & 0.415 & & \\
& & & & & & & \\
$\mathrm{Mo}(3)-\mathrm{O}(6)$ & 0.922 & $\mathrm{Mo}(3)-\mathrm{O}(7)$ & 1.778 & $\mathrm{Mo}(3)-\mathrm{O}(8)$ & 1.680 & & \\
$\mathrm{Mo}(3)-\mathrm{O}(9)$ & 1.054 & $\mathrm{Mo}(3)-\mathrm{O}(10)$ & 0.264 & $\mathrm{Mo}(3)-\mathrm{O}(11)$ & 0.275 & & \\
$\mathrm{P}(1)-\mathrm{O}(2)$ & 1.279 & $\mathrm{P}(1)-\mathrm{O}(10)$ & 1.255 & $\mathrm{P}(1)-\mathrm{O}(11)$ & 1.317 & & \\
$\mathrm{P}(1)-\mathrm{O}(12)$ & 1.167 & & & & & & \\
& & & & & & & \\
\end{tabular}




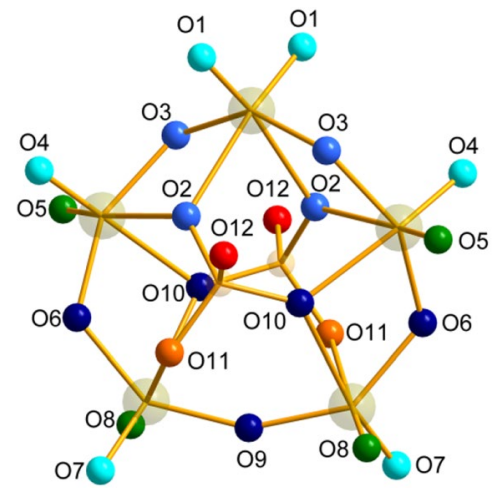

Protonation level $(\Sigma \mathrm{H})$ of $\mathrm{O}$ atoms in EPM

$\begin{array}{cccccc} & & & & & \\ 0.8 & 0.4 & 0.3 & 0.2 & 0.1 & 0.0\end{array}$

Fig. 7 Protonation of oxygen atoms in the unit of EPM. The extent of protonation for each oxygen atom is indicated by different colors

$\boldsymbol{\Sigma} \mathrm{H}$ of $0-0.1$ possess dense electron cloud (see Table 2). The overall proton rate of EPM is 5.924, which is approximately equal to the negative charge on $\left[\mathrm{P}_{2} \mathrm{Mo}_{5} \mathrm{O}_{23}\right]^{6-}$ cluster in EPM. In generally, the multiply protons usually assigned to be delocalized on the whole polyoxoanion, which the phenomenon is common in POM chemistry and has been reported in many leteratures, for example, $\left[\mathrm{Ni}(\text { enMe })_{2}\right]_{3}$ $\left[\mathrm{H}_{6} \mathrm{Ni}_{20} \mathrm{P}_{4} \mathrm{~W}_{34}(\mathrm{OH})_{4} \mathrm{O}_{136}(\mathrm{enMe})_{8}\left(\mathrm{H}_{2} \mathrm{O}\right)_{6}\right] \cdot 12 \mathrm{H}_{2} \mathrm{O}$ [22], and $\left[\mathrm{H}_{3} \mathrm{~W}_{12} \mathrm{O}_{40}\right]^{5-}$ [28]. These results may indicate that most of the counter positive charges in EPM are delocalized in the $\left[\mathrm{P}_{2} \mathrm{Mo}_{5} \mathrm{O}_{23}\right]^{6-}$ skeleton, making EPM not a typical ionic compound. Therefore, the molecule of EPM is designated as $\left\{\left[\mathrm{C}_{2} \mathrm{~N}_{2} \mathrm{H}_{8}\right]_{2}\right\}\left[\mathrm{H}_{6} \mathrm{P}_{2} \mathrm{Mo}_{5} \mathrm{O}_{23}\right]$, which is different from previous report ones $[20,21]$.

\subsection{IR spectra and thermolability}

The IR spectrum of EPM was also investigated (Fig. 8a). The spectrum exhibits characteristic peaks of the Strandberg-type POM at low wave-number regions, in which the characteristic bands between 1003 and $1120 \mathrm{~cm}^{-1}$ are attributed to the $v(\mathrm{P}-\mathrm{O})$ bond and the band at $903 \mathrm{~cm}^{-1}$ is assigned to $v(\mathrm{Mo}=0)$ bond. While the prominent bands in the range of $555-706 \mathrm{~cm}^{-1}$ are attributed to $v$ (Mo-O-Mo) bond [29]. In addition, the occurrence of characteristic vibrations at about 3435 and $1622 \mathrm{~cm}^{-1}$ may be attributed to the $v(\mathrm{~N}-\mathrm{H})$ bond confirms the presence of en ligands [30]. Interestingly, when EPM was heated to more than $60^{\circ} \mathrm{C}$, its appearance changed greatly, from colorless crystal to yellow opaque solid material (see Fig. 8c, d). As shown in Fig. 8b, the IR spectrum of the heated EPM showed a great change, in which the characteristic peaks of the Strandberg-type structure have declined greatly and disappeared. These results may indicate that the structure of $\left[\mathrm{H}_{6} \mathrm{P}_{2} \mathrm{Mo}_{5} \mathrm{O}_{23}\right]$ clusters in the EPM collapsed under more than $60^{\circ} \mathrm{C}$.

The thermal stability over time was further investigated by variable temperature infrared spectra. As shown in Fig. $\mathrm{S} 1$, under $37^{\circ} \mathrm{C}$, the characteristic peaks of $\left[\mathrm{H}_{6} \mathrm{P}_{2} \mathrm{Mo}_{5} \mathrm{O}_{23}\right]$ clusters in EPM were maintained from 0.5 to $24 \mathrm{~h}$, indicating that EPM was relatively thermal stable under $37^{\circ} \mathrm{C}$. While, under $50^{\circ} \mathrm{C}$, as shown in Fig. 9, the characteristic peaks of $\left[\mathrm{H}_{6} \mathrm{P}_{2} \mathrm{Mo}_{5} \mathrm{O}_{23}\right]$ clusters were maintained the beginning from 0.5 to $12 \mathrm{~h}$, afterwards the peaks signal attenuated, which may imply that the EPM became
Fig. 8 IR spectra for EPM (a) and that heated over $60^{\circ} \mathrm{C}(\mathbf{b})$; and the corresponding crystal pictures ( $\mathbf{c}$ for EPM and $\mathbf{d}$ for that heated over $60^{\circ} \mathrm{C}$ )
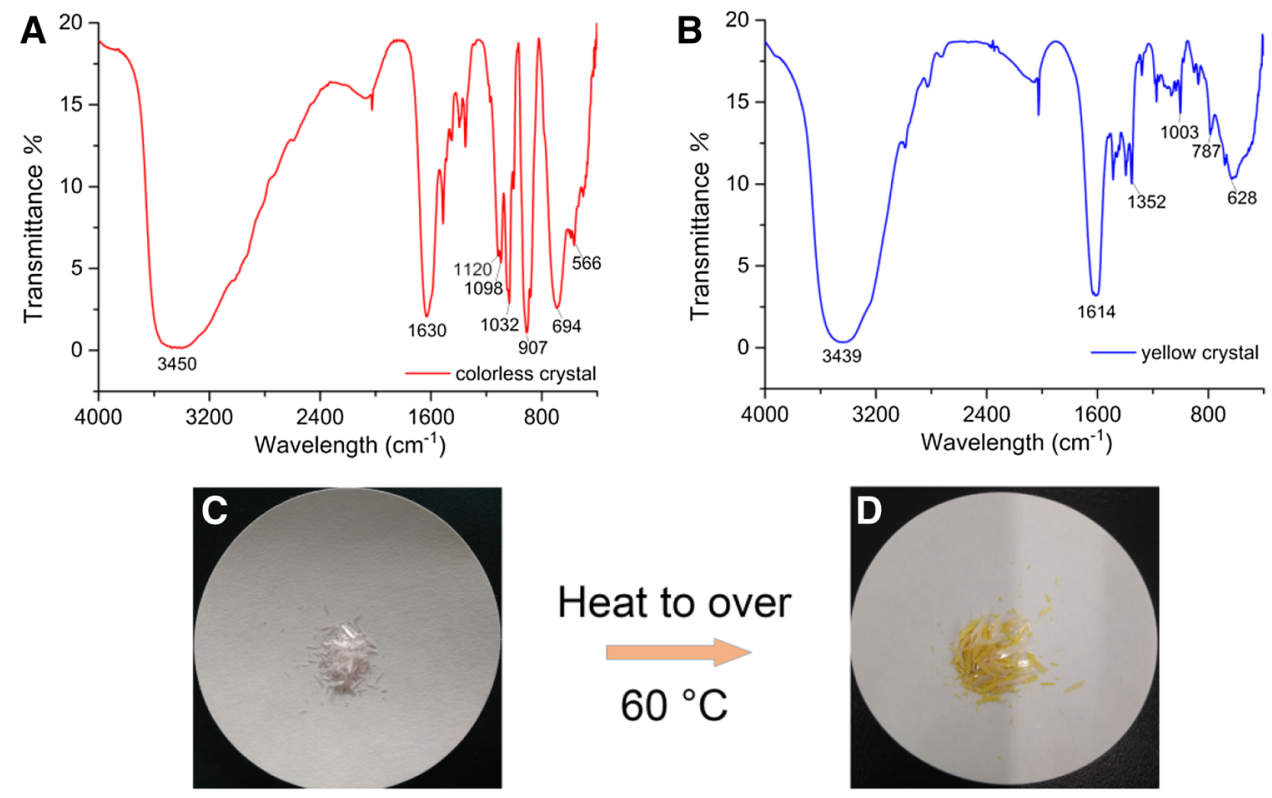

Heat to over
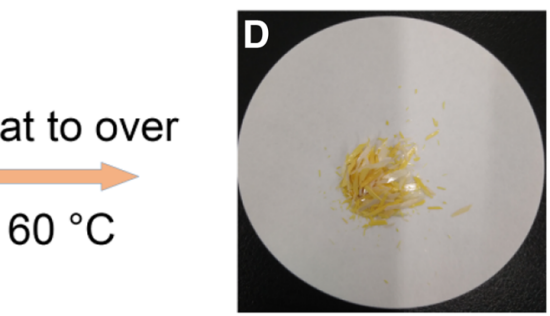
Fig. 9 IR spectra of EPM under $50{ }^{\circ} \mathrm{C}$ from 0.5 to $24 \mathrm{~h}$
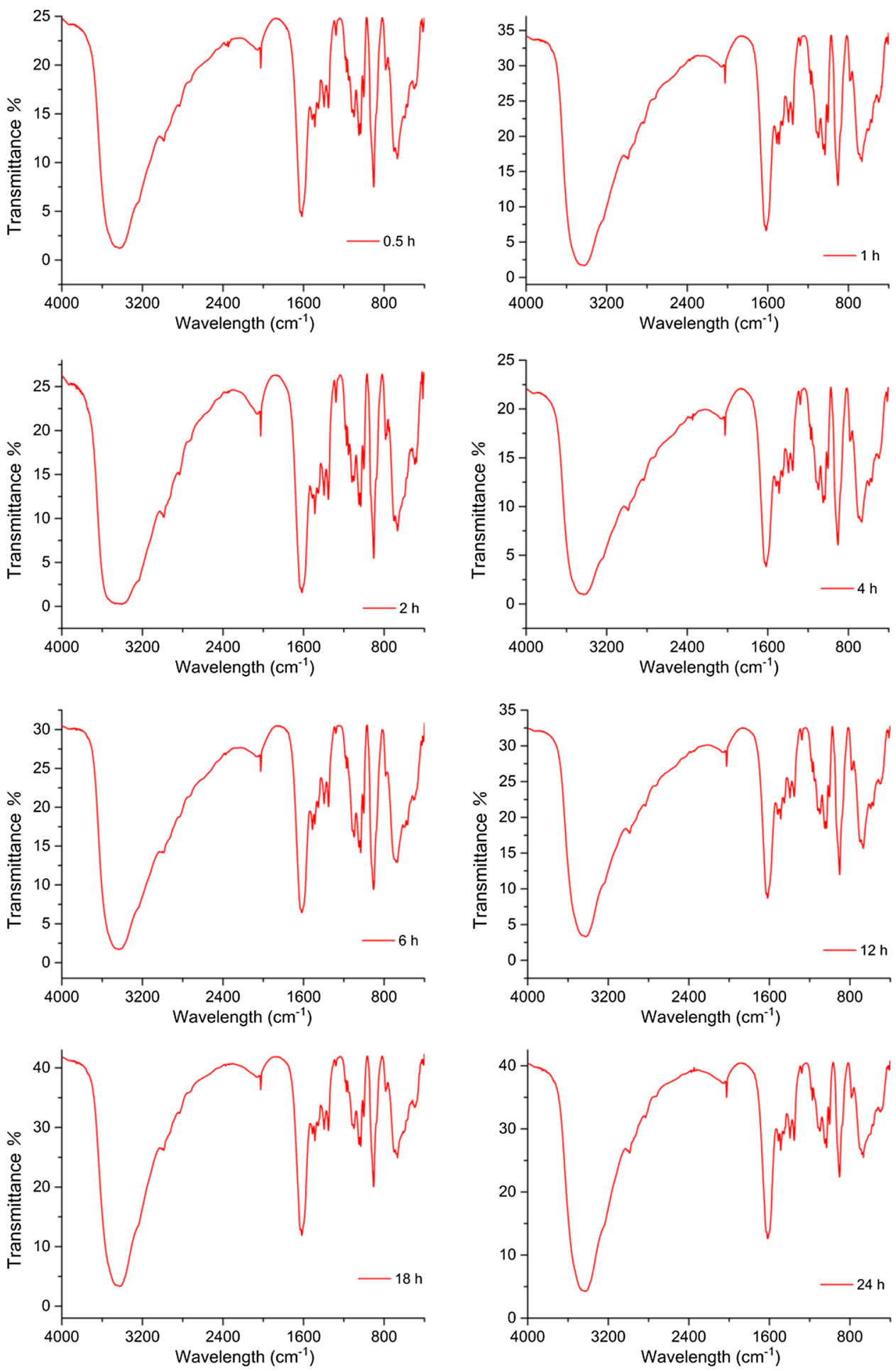

unstable under $50^{\circ} \mathrm{C}$ when the time exceeds $12 \mathrm{~h}$. However, when heated over $60^{\circ} \mathrm{C}$ (see Fig. 8b), the IR spectra of EPM changes greatly, implying that the structure of EPM was unstable over $60^{\circ} \mathrm{C}$.

As shown in Fig. $\mathrm{S2}$, the characteristic peaks of the Strandberg-type structure of EPM were maintained in water for 7 days. These results may imply that although it is thermally unstable in dry conditions, EPM can be kept in aqueous solution for a long time at room temperature, which guarantees that EPM can be applied to mild catalytic reactions and used as precursor for synthetic reactions. 


\section{Conclusions}

A covalent Strandberg-type phosphomolybdate $\left\{\left[\mathrm{C}_{2} \mathrm{~N}_{2} \mathrm{H}_{8}\right]_{2}\right\}\left[\mathrm{H}_{6} \mathrm{P}_{2} \mathrm{Mo}_{5} \mathrm{O}_{23}\right]$ (EPM) has been synthesized and been fully characterized by elemental analyses, $\mathrm{X}$-ray powder diffraction (XRPD), X-ray photoelectron spectra (XPS), IR spectrum, and single-crystal $X$-ray diffraction. A series of detailed work have been done to discuss the necessary and optimal conditions of EPM synthesis. Three key factors were confirmed by parallel experiments, which are en as the temple, $\mathrm{pH}$ and the usage of $\mathrm{Mn}^{2+}$. Furthermore, the thermostability of EPM was also been investigated, which indicated that EPM is thermally unstable over $60^{\circ} \mathrm{C}$. In view of the wide application prospects of Strandberg-type materials, this work will be of great help and reference to the synthesis of new Strandberg-type compounds by using the precursor of $\left[\mathrm{H}_{6} \mathrm{P}_{2} \mathrm{Mo}_{5} \mathrm{O}_{23}\right]$ clusters [22].

Acknowledgements This work was supported by the Research Foundation for Advanced Talents of Shanxi Province (1800006003 and 1800008001), the Research Foundation of Taiyuan Institute of Technology (03000352), and the Research Foundation of the Chinese State Key Laboratory of Coordination Chemistry (SKLCC1912).

\section{Compliance with ethical standards}

Conflict of interest The author(s) declare that they have no competing interests.

\section{References}

1. Du DY, Qin JS, Li SL, Su ZM, Lan YQ (2014) Recent advances in porous polyoxometalate-based metal-organic framework materials. Chem Soc Rev 43:4615-4632

2. Huang JL, Lin LQ, Sun DH, Chen HM, Yang DP, Li QB (2015) Bioinspired synthesis of metal nanomaterials and applications. Chem Soc Rev 44:6330-6374

3. Banerjee A, Bassil BS, Roschenthaler GV, Kortz U (2012) Diphosphates and diphosphonates in polyoxometalate chemistry. Chem Soc Rev 41:7590-7604

4. Fang N, Ji YM, Li CY, Wu YY, Ma CG, Liu HL, Li MX (2017) Synthesis and adsorption properties of $\left[\mathrm{Cu}(\mathrm{L})_{2}\left(\mathrm{H}_{2} \mathrm{O}\right)\right]$ $\mathrm{H}_{2}\left[\mathrm{Cu}(\mathrm{L})_{2}\left(\mathrm{P}_{2} \mathrm{Mo}_{5} \mathrm{O}_{23}\right)\right] \cdot 4 \mathrm{H}_{2} \mathrm{O} / \mathrm{Fe}_{3} \mathrm{O}_{4}$ nanocomposites. Rsc Adv 7:25325-25333

5. Gong $\mathrm{CH}$, Zeng $\mathrm{XH}$, Zhu CF, Shu JH, Xiao PX, Xu H, Liu LC, Zhang JY, Zeng QD, Xie JL (2016) A series of organic-inorganic hybrid materials consisting of flexible organic amine modified polyoxomolybdates: synthesis, structures and properties. RSC Adv 6:106248-106259

6. Ma X, Zhou FT, Yue H, Hua JA, Ma PT (2019) A nano-linear zinc-substituted phosphomolybdate with reactive oxygen species catalytic ability and antibacterial activity. J Mol Struct 1198:126865

7. Jin HJ, Zhou BB, Yu Y, Zhao ZF, Su ZH (2011) Inorganic-organic hybrids constructed from heteropolymolybdate anions and copper-organic fragments: syntheses, structures and properties. CrystEngComm 13:585-590
8. Meng JX, Lu Y, Li YG, Fu H, Wang EB (2011) Controllable selfassembly of four new metal-organic frameworks based on different phosphomolybdate clusters by altering the molar ratio of $\mathrm{H}_{3} \mathrm{PO}_{4}$ and $\mathrm{Na}_{2} \mathrm{MoO}_{4}$. CrystEngComm 13:2479-2486

9. Xu XX, Gao X, Lu TT, Liu XX, Wang XL (2015) Hybrid material based on a coordination-complex-modified polyoxometalate nanorod (CC/POMNR) and PPy: a new visible light activated and highly efficient photocatalyst. J Mater Chem A 3:198-206

10. Feng SL, Lu Y, Zhang YX, Su F, Sang XJ, Zhang LC, You WS, Zhu ZM (2018) Three new Strandberg-type phenylphosphomolybdate supports for immobilizing horseradish peroxidase and their catalytic oxidation performances. Dalton Trans 47:14060-14069

11. Ma Y, Xue Q, Min ST, Zhang YP, Hu HM, Gao SL, Xue GL (2013) An unusual fan-type polyanion with a silver cation located at the axial center, $\left[\mathrm{AgAs}_{2}\left(\mathrm{III}\left(\mathrm{As}^{\mathrm{III}} \mathrm{As}^{\mathrm{V}} \mathrm{Mo}_{4} \mathrm{O}_{18}(\mathrm{OH})_{2}\right)_{3}\right]^{11-}\right.$. Dalton Trans 42:3410-3416

12. Li FY, Xu L (2011) Coordination assemblies of polyoxomolybdate cluster framework: from labile building blocks to stable functional materials. Dalton Trans 40:4024-4034

13. Wang JP, Ma HX, Zhang LC, You WS, Zhu ZM (2014) Two Strandberg-type organophosphomolybdates: synthesis, crystal structures and catalytic properties. Dalton Trans 43:17172-17176

14. Li ZL, Wang Y, Zhang LC, Wang JP, You WS, Zhu ZM (2014) Three molybdophosphates based on Strandberg-type anions and $\mathrm{Zn}$ (ii)- $\mathrm{H}_{2}$ biim/ $\mathrm{H}_{2} \mathrm{O}$ subunits: syntheses, structures and catalytic properties. Dalton Trans 43:5840-5846

15. Ma X, Zhang C, Hua JA, Ma PT, Wang JP, Niu JY (2019) A binuclear copper-substituted phosphomolybdate with reactive oxygen species catalytic ability and antimicrobial activity. CrystEngComm 21:394-398

16. Ma $X$, Hua JA, Wang $K$, Zhang HM, Zhang $C L$, He YF, Guo ZJ, Wang XY (2018) Modulating conformation of $A \beta$-peptide: an effective way to prevent protein-misfolding disease. Inorg Chem 57:13533-13543

17. Brese NE, O'Keeffe M (1991) Bond-valence parameters for solids. Acta Crystallogr B47:192-197

18. Sheldrick GM (1997) SHEXTL-97, programs for crystal structure refinements. University of Göttingen, Göttingen

19. SAINT (2007) Bruker AXS Inc.: Madison, WI

20. Asnani M, Kumar D, Duraisamy T, Ramanan A (2012) Crystallization of organically templated phosphomolybdate cluster-based solids from aqueous solution. J Chem Sci 124:1275-1286

21. Sun $Q Z$, Zhang $H H$, Huang $C C$, Sun $Q H$, Sun $R Q$, Wang $Y J$ (2003) Bis-(ethylenediammonium)di- $\mu_{5}$-hydrogenphosphatopenta- $\mu_{2}$-oxo-decaoxo-pentamolybdenum. Acta Crystallogr E59:m729-m730

22. Yang L, Ma X, Ma PT, Hua JA, Niu JY (2013) A series of arsenotungstates based on the $\left[\mathrm{HAs}_{2} \mathrm{~W}_{8} \mathrm{O}_{31}\right]^{7-}$ building block: syntheses by control of the reaction process. Cryst Growth Des 13:2982-2989

23. Zhang YP, Li LL, Sun T, Liu B, Hu HM, Xue GL (2011) A cagelike polyanion with a $\mathrm{Ag}^{+}$enwrapped, $\left[\mathrm{AgAs}_{2} \mathrm{Mo}_{15} \mathrm{O}_{54}\right]^{11-}$. Inorg Chem 50:2613-2618

24. Yang DH, Li SZ, Ma PT, Wang JP, Niu JY (2013) Carboxylate-functionalized phosphomolybdates: ligand-directed conformations. Inorg Chem 52:8987-8992

25. Zheng ST, Zhang J, Juan JM, Yuan DQ, Yang GY (2009) Poly(polyoxotungstate)s with 20 nickel centers: from nanoclusters to one-dimensional chains. Angew Chem Int Ed 48:7176-7179

26. Ma X, Ma PT, Zhang DD, Hua JA, Zhang C, Huang TF, Wang JP, Niu JY (2013) A novel sandwich-type tungstoarsenate containing a cagelike Ca6 cluster with a water molecule enwrapped. Dalton Trans 42:874-878 
27. Brown ID, Altermatt D (1985) Bond-valence parameters obtained from a systematic analysis of the inorganic crystal structure database. Acta Crystallogr Sect B: Struct Sci 41:244-247

28. Streb C, Ritchie C, Long DL, Kögerler P, Cronin L (2007) Modular assembly of a functional polyoxometalate-based open framework constructed from unsupported $\mathrm{Ag}^{\mathrm{l}}$.... $\mathrm{Ag}^{\mathrm{l}}$ interactions. Angew Chem Int Ed 46:7579-7582

29. Packiam DEJ, Vidyasagar K (2017) Syntheses and characterization of phosphonates and diphosphonates of molybdenum, $\mathrm{A}_{4}\left[\left(\mathrm{MoO}_{3}\right)_{5}\left(\mathrm{O}_{3} \mathrm{PR}\right)_{2}\right] \cdot \mathrm{xH}_{2} \mathrm{O}, \mathrm{A}_{2}\left[\mathrm{Mo}_{2} \mathrm{O}_{5}\left(\mathrm{O}_{3} \mathrm{PR}\right)_{2}\right]$ and $\mathrm{A}_{2}\left[\mathrm{Mo}_{2} \mathrm{O} 5\left(\mathrm{O}_{3} \mathrm{P}-\mathrm{R}-\mathrm{PO}_{3}\right)\right]\left(\mathrm{A}=\mathrm{K}, \mathrm{Rb}, \mathrm{Cs}, \mathrm{Tl}, \mathrm{NH}_{4}\right)$. Dalton Trans 46:16102-16112
30. Niu JY, Hua JA, Ma X, Wang JP (2012) Temperature-controlled assembly of a series of inorganic-organic hybrid arsenomolybdates. CrystEngComm 14:4060-4067

Publisher's Note Springer Nature remains neutral with regard to jurisdictional claims in published maps and institutional affiliations. 